INFLAMMATORY BOWEL DISEASE

\title{
Infliximab for the treatment of pyoderma gangrenosum: a randomised, double blind, placebo controlled trial
}

\author{
T N Brooklyn, M G S Dunnill, A Shetty, J J Bowden, J D L Williams, C E M Griffiths, \\ A Forbes, R Greenwood, C S Probert
}

See end of article for authors' affiliations

Correspondence to: Dr C S Probert, Bristol Royal Infirmary, Bristol BS2 8HW, UK; c.s.j.probert@ bristol.ac.uk

Revised version received 21 September 2005 Accepted for publication 21 September 2005 Published online first 27 September 2005

\begin{abstract}
Background: Pyoderma gangrenosum (PG) is a chronic ulcerating skin condition that often occurs in association with inflammatory bowel disease. There have been a number of reports of PG responding to infliximab, a monoclonal antibody against tumour necrosis factor $\alpha$.

Aim: In the first randomised placebo controlled trial of any drug for the treatment of PG, we have studied the role of infliximab in this disorder.

Subjects: Patients 18 years of age or older with a clinical diagnosis of PG were invited to take part. Methods: Patients were randomised to receive an infusion of infliximab at $5 \mathrm{mg} / \mathrm{kg}$ or placebo at week 0 . Patients were then assessed at week 2 and non-responders were offered open labelled infliximab. The primary end point was clinical improvement at week 2, with secondary end points being remission and improvement at week 6 .

Results: Thirty patients were entered into the study. After randomisation, 13 patients received infliximab and 17 patients received placebo. At week 2, significantly more patients in the infliximab group had improved (46\% (6/13)) compared with the placebo group (6\% (1/17); $p=0.025)$. Overall, 29 patients received infliximab with $69 \%(20 / 29)$ demonstrating a beneficial clinical response. Remission rate at week 6 was $21 \%(6 / 29)$. There was no response in $31 \%(9 / 29)$ of patients.

Conclusions: This study has demonstrated that infliximab at a dose of $5 \mathrm{mg} / \mathrm{kg}$ is superior to placebo in the treatment of PG. Open label treatment with infliximab also produced promising results. Infliximab treatment should be considered in patients with PG.
\end{abstract}

\section{METHODS}

\section{Patients}

Approval for the study was obtained from the South-West England Multi-Centre Research Ethics Committee and from each of the local institutions. Eligible patients included men and women 18 years of age or older with a clinical diagnosis of PG, irrespective of whether they had IBD. The diagnosis of PG was made by a dermatologist or experienced gastroenterologist and was made on clinical grounds if the typical purple undermined edge was present. A skin biopsy was not required for the diagnosis as there are no diagnostic histological features of PG. Where there was clinical doubt in the diagnosis, a biopsy and wound swab were taken to exclude other conditions. Patients were screened prior to entry and written informed consent obtained. At the screening visit, all patients underwent a physical examination and a chest $x$ ray. Patients with $x$ rays suspicious of previous tuberculosis infection were offered a Heaf (PPD) test. Patients with a positive Heaf test and those with New York grade III or IV heart failure were excluded. A total of 31 patients were screened and 30 underwent randomisation. Patients were stratified into three subgroups; patients with IBD, patients without IBD, and patients with peristomal PG. Randomisation took into account stratification of the patients.

\section{Study design}

The study was a multicentre, randomised, double blind, placebo controlled trial of infliximab for the treatment of PG involving four centres in the UK: Bristol, Gloucester, London, and Manchester. Patients were randomised to receive infliximab at a dose of $5 \mathrm{mg} / \mathrm{kg}$ or placebo at week 0 and

Abbreviations: PG, pyoderma gangrenosum; IBD, inflammatory bowel disease; TNF- $\alpha$, tumour necrosis factor $\alpha$; DLQI, dermatology life quality index 
then reassessed two weeks later. If there was no clinical improvement at week 2, they were then offered open label treatment with infliximab at $5 \mathrm{mg} / \mathrm{kg}$. Further clinical assessments occurred at weeks 4 and 6 .

The methods chosen for assessing the response to treatment were a clinician's and patient's assessment that was based on the appearance of the ulcer. Improvement was based on a reduction in ulcer size and depth as well as an assessment of the degree of undermining of the ulcer edge. In order to provide objective evidence of these assessments, a photograph of the ulcer was taken at each visit. Patients were also required to complete two quality of life questionnaires at each visit. Clinical assessments after treatment classified the ulcers as "no improvement", "improved", or "remission" (figs 1-3) The questionnaires used were the dermatology life quality index (DLQI) and the EuroQol. ${ }^{15}{ }^{16} \mathrm{~A}$ pharmacist prepared each infusion of infliximab or an identical appearing placebo. Neither the patients nor the investigators were aware of the treatment assignment. The dose of all concomitantly taken medications remained constant during the study period.

\section{End points}

The primary end point was clinical improvement at week 2 , as determined by the clinician and patient's global assessment. Secondary end points were clinical remission and clinical improvement at week 6 and improvement in quality of life scores at week 6. Adverse events were recorded for each patient.
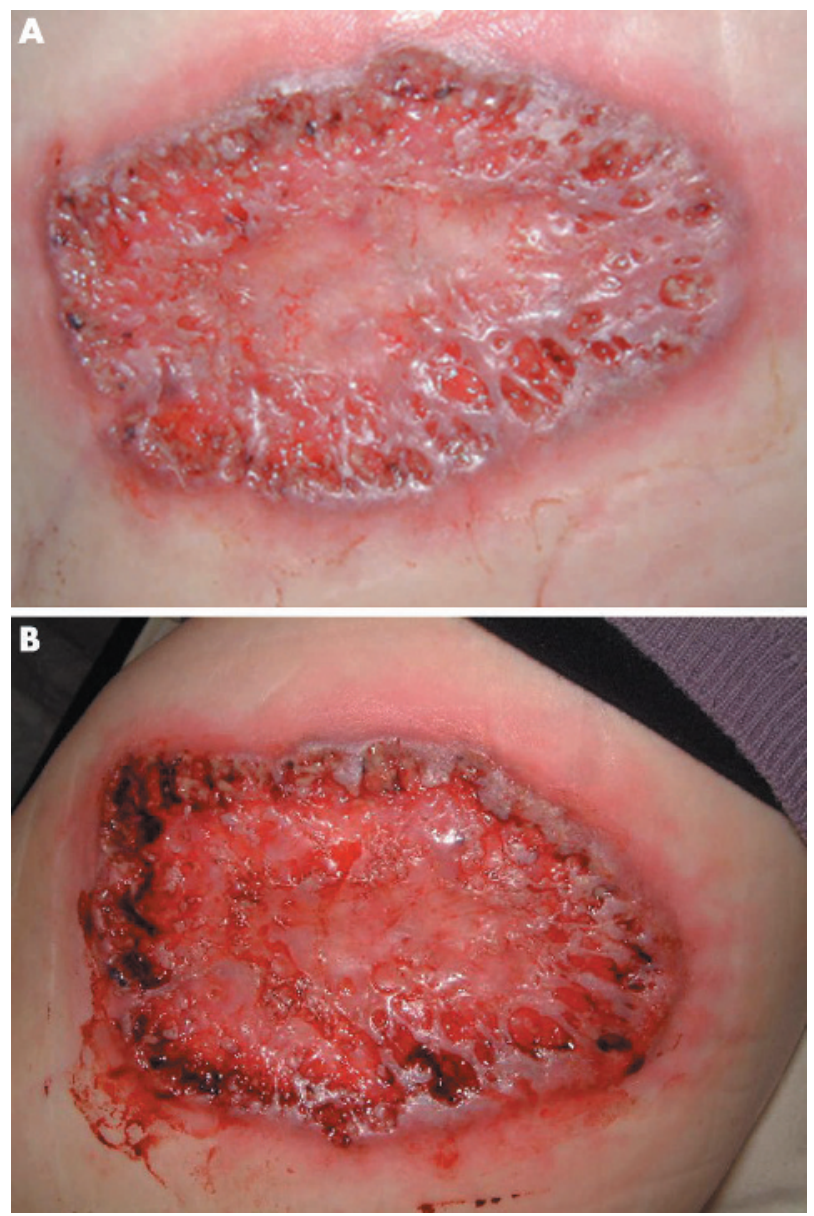

Figure 1 This shows an ulcer that was classified as "No improvement" at week 2 (published with written consent).
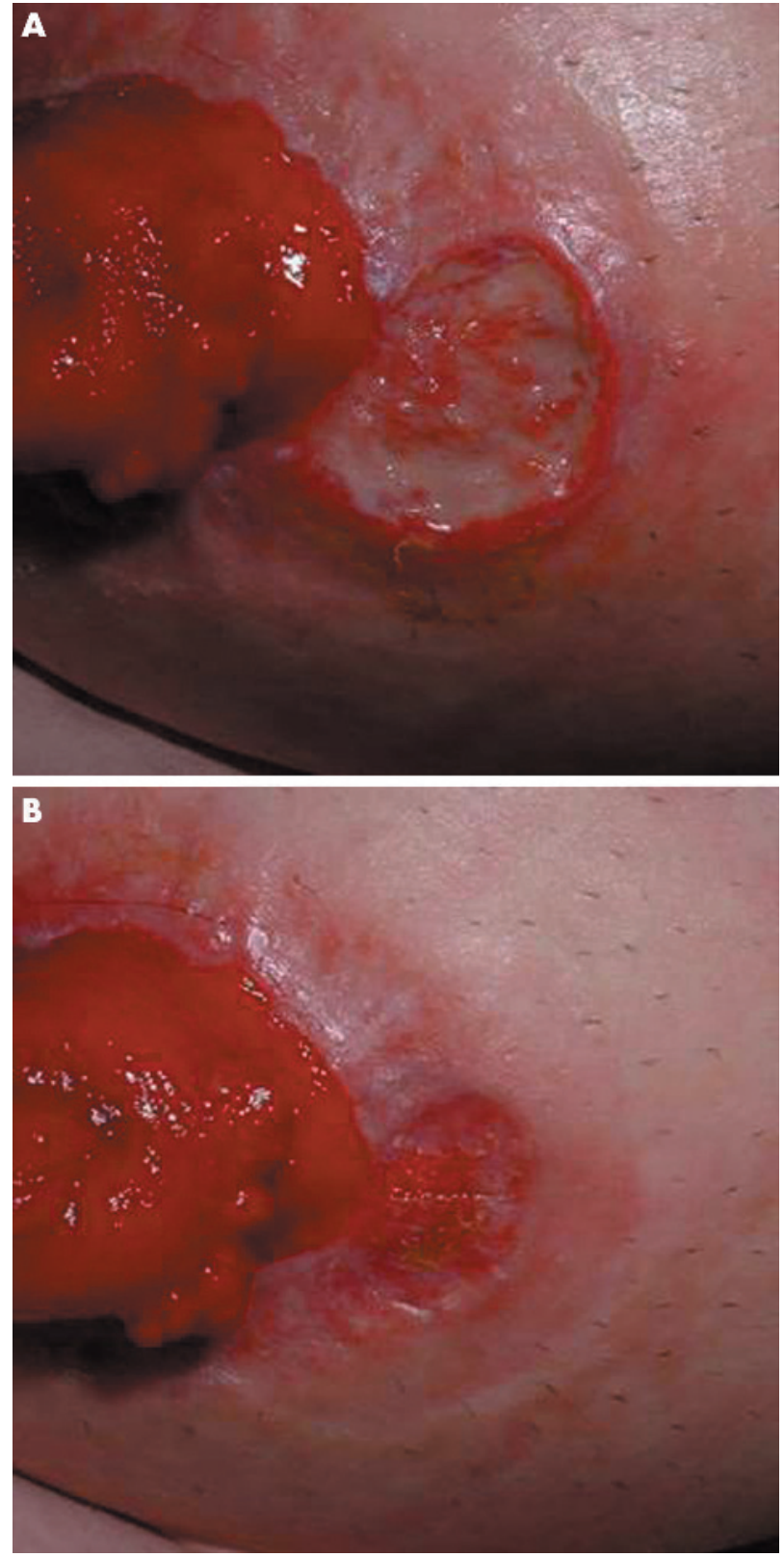

Figure 2 This shows an ulcer that was classified as "Improvement" at week 2 (published with written consent).

\section{Statistical analysis}

The prospective primary hypothesis was that one infusion of infliximab at a dose of $5 \mathrm{mg} / \mathrm{kg}$ would result in a higher proportion of patients clinically improving at week 2 than placebo. All efficacy analyses were conducted according to the intention to treat principle, with the last observation carried forward, and thus included all 30 patients who received an infusion.

All statistical tests were two sided, with an alpha level of 0.05. Response rates were compared using Fisher's exact test. We estimated that 18 patients would be needed in each group to detect a significant difference in response rates at a power of $80 \%$ and a $5 \%$ level of significance. We assumed a response rate of $40 \%$ in the infliximab group and a response rate of $5 \%$ in the placebo group. Ethics approval for the study allowed for the recruitment of patients over a three year period but PG is a rare condition and despite actively canvassing for patients in all centres the intended number of 36 patients was not 

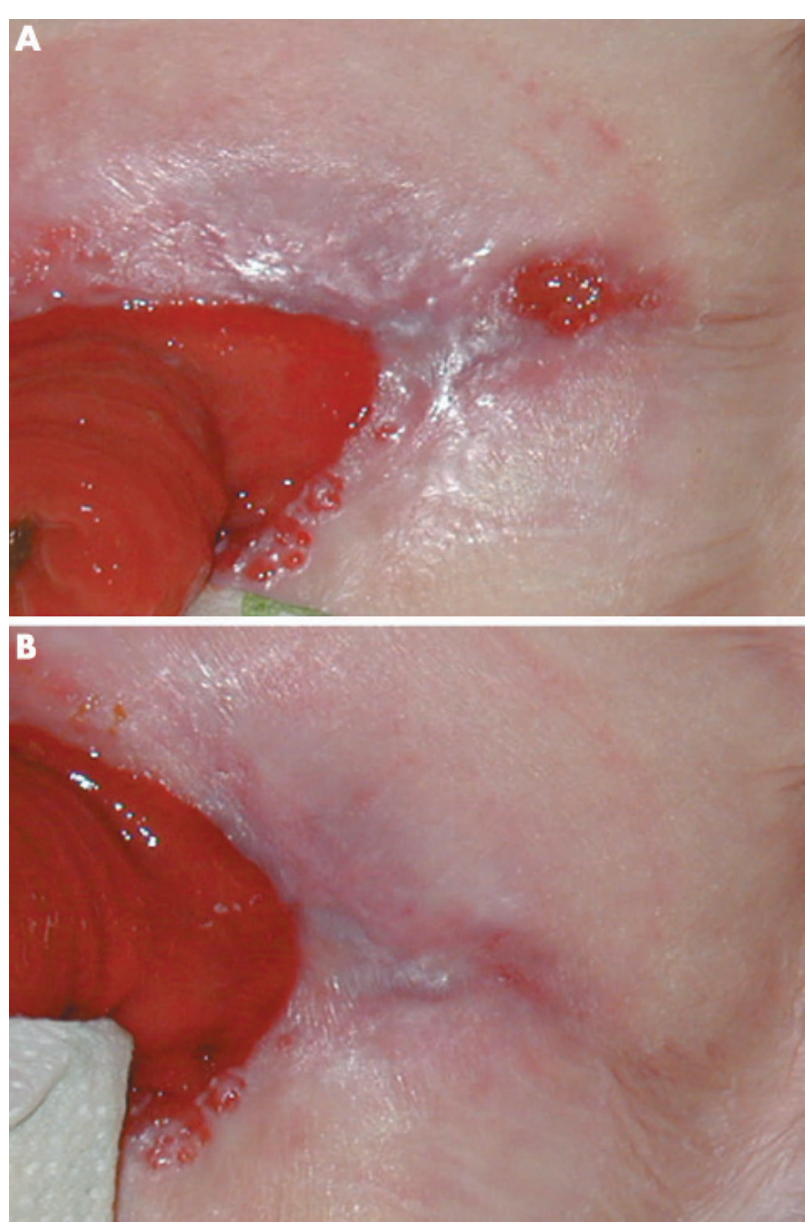

Figure 3 This shows an ulcer that was classified as "Remission" at week 2 (published with written consent).

reached by the end of the study period. This resulted in a disparity in the randomisation, as will be seen later.

As the two quality of life questionnaires EuroQol and DLQI were thought not to have a normal distribution, nonparametric and graphical methods were used to investigate whether they had improved over time. Change in quality of life measures at week 2 was investigated using absolute change from baseline (week 2 minus baseline) for both measures. The resulting improvement score was then analysed using a Mann-Whitney test to investigate whether there was any difference between the infliximab and placebo groups. Data were also investigated graphically using box plots.

\section{RESULTS}

There were no significant differences in demographic characteristics, DLQI scores, EuroQol scores, or prior or current medications between the two groups at baseline (table 1). Thirty one patients were screened but one was ineligible because of a strongly positive Heaf test.

After randomisation, 13 patients received infliximab at a dose of $5 \mathrm{mg} / \mathrm{kg}$ and 17 patients received placebo. At week 2, significantly more patients in the infliximab group had improved $(46 \% ; 6 / 13)$ compared with the placebo group $(6 \%$; $1 / 17 ; \mathrm{p}=0.025$ )

The 23 patients who had not improved by week 2 were offered open label infliximab; all accepted the treatment. This meant that, overall, 29 patients received infliximab. At weeks 4 and $6,69 \%(20 / 29)$ of patients who had received infliximab had improved, including $21 \%(6 / 29)$ who were in complete
Table 1 Demographics of patients with pyoderma gangrenosum (PG) entered into the study

\begin{tabular}{|c|c|c|}
\hline & $\begin{array}{l}\text { Infliximab group } \\
(n=13)\end{array}$ & $\begin{array}{l}\text { Placebo group } \\
(n=17)\end{array}$ \\
\hline Age (y) & $50(20-80)$ & $55(33-81)$ \\
\hline $\operatorname{Sex}(M: F)$ & $6: 7$ & $7: 10$ \\
\hline $\mathrm{IBD}$ & $7 / 13$ & $12 / 17$ \\
\hline Crohn's disease & $5 / 7$ & $8 / 12$ \\
\hline Ulcerative colitis & $2 / 7$ & $4 / 12$ \\
\hline Duration of PG (weeks) ${ }^{*}$ & $26(2-676)$ & $12(2-288)$ \\
\hline \multicolumn{3}{|l|}{ Site of PG } \\
\hline Limbs & 7 & 8 \\
\hline Peristomal & 4 & 6 \\
\hline Perineum & 2 & 3 \\
\hline DLQI score & 9 & 8 \\
\hline EuroQol score & 12 & 12 \\
\hline \multicolumn{3}{|l|}{ Concomitant medication } \\
\hline Minocycline & 1 & 0 \\
\hline Prednisolone & 7 & 5 \\
\hline Methotrexate & 0 & 2 \\
\hline Tacrolimus paste & 1 & 1 \\
\hline Topical steroid & 1 & 2 \\
\hline
\end{tabular}

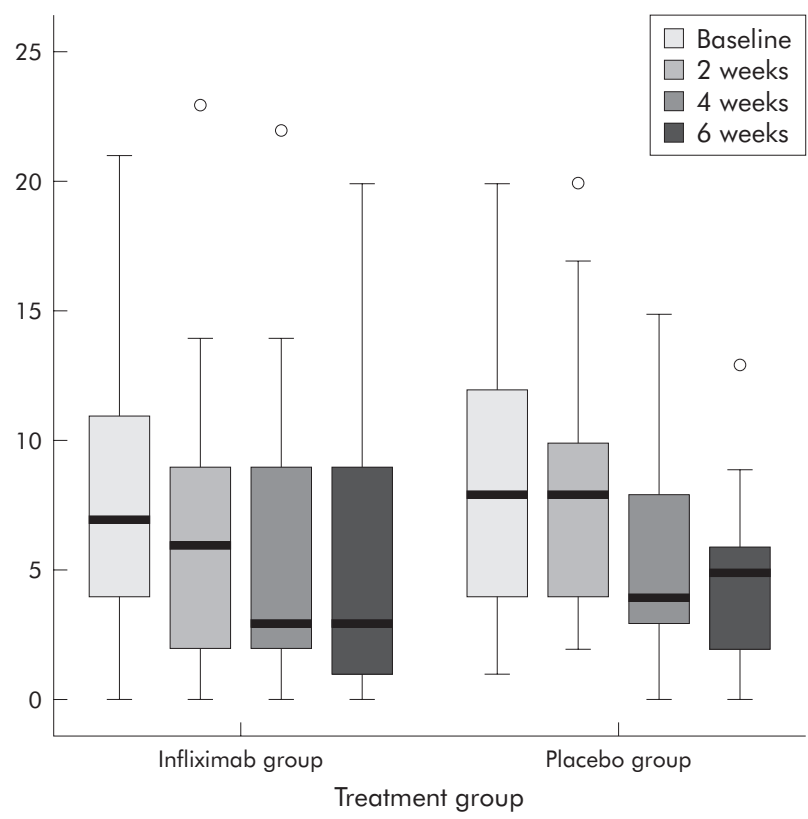

Figure 4 Dermatology life quality index (DLQI) scores for the placebo and infliximab therapy groups. Using the DLQI, lower scores indicate health, and this shows a reduction in the scores after infusion of infliximab at week 2 in the infliximab group and at week 4 in the placebo group.

remission at week 6 . There was no response in 31\% (9/29) of treated patients.

There were seven patients who received two doses of infliximab because there was no improvement at week 2 . Of these, $43 \%$ (3/7) had improved by week 6, including one patient in complete remission.

The DLQI questionnaire showed an improvement in median scores after patients received infliximab, as demonstrated in fig 4 in the infliximab treatment group at week 2 and at week 4 in the placebo group after open label treatment. The EuroQol scores also showed improvement at week 4 in both groups although the week 2 result was more ambiguous (fig 5). Statistically, the change in quality of life measures at week 2 was very minimal, with median values of zero for both measures in both groups. The $\mathrm{p}$ values for the 


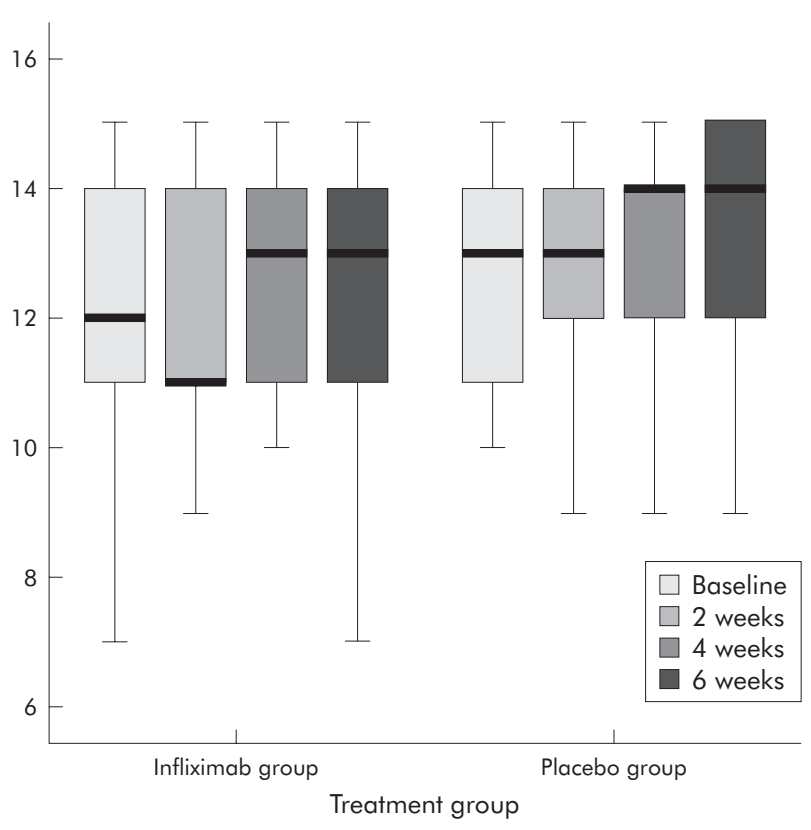

Figure 5 EuroQol scores for the placebo and infliximab therapy groups. Using the EuroQol, higher scores indicate health, and this shows an improvement in the scores at week 4 in both groups.

differences between the infliximab and placebo groups were 0.849 for the EuroQol and 0.435 for the DQLI score. Figure 4 suggests that week 2 may be too early for significant improvements in quality of life to become apparent.

The data were analysed further to assess whether particular subgroups were more likely to respond to infliximab than others. This analysis is presented in table 2.

Subgroup analysis suggests that there was no difference in response according to sex or the coexistence of IBD. Patients with involvement of the perineum and patients with ulcerative colitis appeared to have a slightly less favourable response but interpretation of these data needs caution as the numbers are very small. More convincing are the data relating to the duration of PG where the response in those with PG of less then 12 weeks' duration was over $90 \%$, compared with a less than $50 \%$ response in those with disease present for more than three months. This probably reflects the fact that recalcitrant PG, that has been resistant to other therapies, remains difficult to treat.
Adverse effects were reported in four patients: these were minor in two patients. One patient in the placebo group reported muscle aches for 48 hours following the open label infusion and another patient in the placebo group developed a herpes simplex lesion on the upper lip four days following open label treatment. There were two serious adverse events. A 67 year old man in the infliximab group required admission to hospital with congestive cardiac failure and fast atrial fibrillation two weeks after the initial infusion. He was not known to have pre-existing heart disease, but infliximab may have precipitated this episode. He responded well to conventional treatment for this and his PG improved. A 75 year old woman in the placebo group who was taking prednisolone and methotrexate for PG involving the labia and buttock developed a methicillin resistant Staphylococcus aureus septicaemia following the open label infusion of infliximab. Prior to her deterioration, she had developed an ulcer on the right leg (not PG) and had been treated for pneumonia. The source of the methicillin resistant Staphylococcus aureus was not identified. She developed multiorgan failure and died in the intensive care unit seven days following administration of infliximab.

\section{DISCUSSION}

This study included patients identified with PG, irrespective of whether they had associated IBD. We observed a rapid and significant clinical response, with $46 \%$ of the infliximab group improving within two weeks compared with just $6 \%$ of patients in the placebo arm. The response at weeks 4 and 6 included patients who had open label infliximab. Overall, the response rate to infliximab was $69 \%$, with a remission rate of $21 \%$. The study demonstrated no difference in outcome between patients with IBD (67\% responders) and those without (73\% responders). The study also demonstrated an improvement in the quality of life of patients with PG following administration of infliximab although this did not reach statistical significance. This is an important consideration in the management of what is often a chronic and painful condition.

Conventional management of PG includes topical therapy, often in combination with systemic agents. Local treatment includes dressings, topical corticosteroids, ${ }^{17}$ topical tacrolimus, ${ }^{18}$ and intralesional injection of corticosteroids. ${ }^{19}$ The mainstay of systemic treatment is immunosuppression, although antimicrobial treatments such as minocycline have also been used with some success. ${ }^{20}$ Oral corticosteroids are most often used initially, but a number of other immunomodulators have been used in the management of $\mathrm{PG}^{5}$

\begin{tabular}{|c|c|c|c|c|}
\hline & Improved (\%) & Remission (\%) & No response (\%) & $\mathrm{p}$ Value \\
\hline \multicolumn{5}{|l|}{ Site of PG } \\
\hline Limbs $(n=15)$ & $12(80)$ & $4(27)$ & $3(20)$ & \\
\hline Peristomal $(n=9)$ & $6(67)$ & $2(22)$ & $3(33)$ & \\
\hline Perineum $(n=5)$ & $2(40)$ & 0 & $3(60)$ & 0.284 \\
\hline \multicolumn{5}{|l|}{ Sex } \\
\hline Male $(n=13)$ & $9(69)$ & $3(23)$ & $4(31)$ & \\
\hline Female $(n=16)$ & $11(69)$ & $3(19)$ & $5(31)$ & 1.000 \\
\hline \multicolumn{5}{|l|}{ Coexisting disease } \\
\hline No IBD $(n=11)$ & $8(73)$ & $2(18)$ & $3(27)$ & \\
\hline $\operatorname{IBD}(n=18)$ & $12(67)$ & $4(22)$ & $6(33)$ & 1.00 \\
\hline Ulcerative colitis $(n=6)$ & $3(50)$ & 0 & $3(50)$ & \\
\hline Crohn's disease $(n=12)$ & $9(75)$ & $4(33)$ & $3(25)$ & 0.593 \\
\hline \multicolumn{5}{|l|}{ Duration of PG } \\
\hline$\leqslant 12$ weeks $(n=14)$ & $13(93)$ & $4(31)$ & $1(7)$ & \\
\hline$\geqslant 12$ weeks $(n=15)$ & $7(47)$ & $2(13)$ & $8(53)$ & 0.014 \\
\hline Total $(n=29)$ & $20(69)$ & $6(21)$ & $9(31)$ & \\
\hline
\end{tabular}


Ciclosporin is commonly used in patients with steroid resistant PG and a number of case series have been reported. ${ }^{21-24}$ The potential side effects from ciclosporin are well documented and include nephrotoxicity, hypertension, and opportunistic infection. ${ }^{5}$ Reports of adverse events are sparse, but there have been deaths related to sepsis and Pneumocystis carinii pneumonia. ${ }^{25}$ Other drugs such as azathioprine, $^{24}$ tacrolimus, ${ }^{26}$ methotrexate, ${ }^{27}$ and cyclophosphamide $^{5}$ have also been used with success. These drugs all have potential for harm, including myelosuppression, nephrotoxicity, hepatotoxicity and, in the case of cyclophosphamide, haemorrhagic cystitis. Serious side effects from the use of these drugs in the treatment of PG are rare. ${ }^{5}$ Ultimately, treatment of PG is empirical as there have been no other randomised controlled trials.

The pathogenesis of PG remains unknown but the association of this condition with IBD and rheumatoid arthritis makes it likely that TNF- $\alpha$ plays an integral role in the development of the disease. A number of case reports have demonstrated a good response of PG to treatment with infliximab or etanercept. ${ }^{6-14}$ Recently, Regueiro et al presented a series of 13 patients with PG associated with IBD that were treated with infliximab. They reported complete healing of PG in all 13 of the patients, although 10 of the patients required multiple infusions of infliximab to keep them in remission. All of the patients were able to discontinue corticosteroids. ${ }^{13}$

The lower remission rate achieved by our patients compared with those reported by Regueiro et al, may relate to the number of infusions received. In their series, patients received a median of eight infusions of infliximab (range 124) and six patients were placed on maintenance infusions. ${ }^{13}$ It is likely that healing of the ulcers relates to their size at the outset of treatment and larger ulcers are likely to require multiple infusions of infliximab in order to achieve remission. It is possible that PG, rather like fistulising Crohn's disease $^{28}$ or psoriasis, ${ }^{29}$ would benefit from an induction dosing regimen with three infusions at weeks 0,2 , and 6 . This study was designed prior to induction dosing becoming commonplace and so did not address this question. By giving fewer infusions, we may have just induced partial healing rather than complete remission. In this study, seven patients failed to improve after infliximab at week 2 and went on to have open label treatment. In other words, these seven patients received two doses of infliximab. By week 6, three of them had improved, including one in remission, suggesting that there may be a benefit from repeated dosing. The role of infliximab in maintaining remission in PG remains unclear although it should be an option considered by clinicians in patients who respond well to the initial infliximab infusion. Use of concomitant immunomodulators such as azathioprine or methotrexate with infliximab is currently accepted practice in IBD as these drugs are helpful in preventing the formation of antibodies to infliximab. ${ }^{30}$ It is likely that they should also be prescribed when using infliximab for the treatment of PG and may have an added benefit.

This short term study has demonstrated that infliximab at a dose of $5 \mathrm{mg} / \mathrm{kg}$ is superior to placebo in the treatment of PG. Open label treatment with infliximab also produced promising results. Infliximab treatment should be considered in patients with PG, irrespective of whether or not they have coexistent IBD. Studies comparing infliximab to conventional treatments such as corticosteroids and ciclosporin may further define the role of infliximab in the management of PG.

\section{Authors' affiliations}

T N Brooklyn, M G S Dunnill, R Greenwood, C S Probert, Bristol Royal Infirmary, Bristol, UK
A Shetty, A Forbes, St Marks Hospital, Harrow, UK J J Bowden, J D L Williams, C E M Griffiths, The Dermatology Centre, Hope Hospital, The University of Manchester, Manchester, UK

This study was supported by a grant from Schering-Plough Ltd. This was an investigator instigated study and the company played no role in study design; collection, analysis, or interpretation of the data; in the writing of the report; or in the decision to submit the paper for publication.

Conflict of interest: None declared.

\section{REFERENCES}

1 Bennett ML, Jackson JM, Jorizzo JL, et al. Pyoderma gangrenosum. A comparison of typical and atypical forms with an emphasis on time to remission. Case review of 86 patients from 2 institutions. Medicine (Baltimore) 2000;79:37-46.

2 Callen JP. Pyoderma gangrenosum. Lancet 1998;351:581-5.

3 von den Driesch P. Pyoderma gangrenosum: a report of 44 cases with followup. $\mathrm{Br} J$ Dermatol 1997;137:1000-5.

4 Powell FC, Schroeter AL, Su WP, et al. Pyoderma gangrenosum: a review of 86 patients. Q J Med 1985;55:173-86.

5 Chow RK, Ho VC. Treatment of pyoderma gangrenosum. J Am Acad Dermatol 1996;34:1047-60.

6 Botros N, Pickover L, Das KM. Image of the month. Pyoderma gangrenosum caused by ulcerative colitis. Gastroenterology. 2000;1 18: 654, 809).

7 Hong JJ, Merel NH, Hanauer SB. Treatment of pyoderma gangrenosum (PG) complicating Crohn's disease (CD) with infliximab. Gastroenterology $2001 ; 120$ (Suppl 1):3153

8 Arnott ID, McDonald D, Williams A, et al. Clinical use of Infliximab in Crohn's disease: the Edinburgh experience. Aliment Pharmacol Ther 2001;15:1639-46.

9 Tan MH, Gordon M, Lebwohl O, et al. Improvement of pyoderma gangrenosum and psoriasis associated with Crohn disease with anti-tumor necrosis factor alpha monoclonal antibody. Arch Dermatol 2001;137:930-3.

10 Batres LA, Mamula P, Baldassano RN. Resolution of severe peristomal pyoderma gangrenosum with infliximab in a child with Crohn disease. J Pediatr Gastroenterol Nutr 2002;34:558-60.

11 Triantafillidis JK, Cheracakis $P$, Sklavaina $M$, et al. Favorable response to infliximab treatment in a patient with active Crohn disease and pyoderma gangrenosum. Scand J Gastroenterol 2002;37:863-5.

12 Liung T, Staun $M$, Grove $O$, et al. Pyoderma gangrenosum associated with Crohn disease: effect of TNF-alpha blockade with infliximab. Scand J Gastroenterol 2002;37:1108-10.

13 Regueiro $M$, Valentine J, Plevy S, et al. Infliximab for treatment of pyoderma gangrenosum associated with inflammatory bowel disease. Am J Gastroenterol 2003;98:1821-6.

14 McGowan JW, Johnson CA, Lynn A. Treatment of pyoderma gangrenosum with etanercept. J Drugs Dermatol 2004;3:441-4.

15 Finlay AY, Khan GK. Dermatology life quality index (DLQI) - a simple practical measure for routine clinical use. Clin Exp Dermatol 1994;19:210-16.

16 The EuroQol Group. EuroQol-a new facility for the measurement of healthrelated quality of life. Health Policy 1990;16:199-208.

17 Wenzel J, Gerdsen R, Phillipp-Dormston W, et al. Topical treatment of pyoderma gangraenosum. Dermatology 2002;205:221-3.

18 Lyon CC, Stapleton M, Smith AJ, et al. Topical tacrolimus in the management of peristomal pyoderma gangrenosum. J Dermatolog Treat 2001;12:13-17.

19 Goldstein F, Krain R, Thornton JJ. Intralesional steroid therapy of pyoderma gangrenosum. J Clin Gastroenterol 1985;7:499-501.

20 Davies MG, Piper S. Pyoderma gangrenosum: successful treatment with minocycline. Clin Exp Dermatol 1981;6:219-23.

21 Curley RK, Macfarlane AW, Vickers CF. Pyoderma gangrenosum treated with cyclosporin A. Br J Dermatol 1985;113:601-4.

22 Duffill MB. Cyclosporine, azathioprine and local therapy for pyoderma gangrenosum. Australas J Dermatol 1994;35:15-18.

23 Carp JM, Onuma E, Das K, et al. Intravenous cyclosporine therapy in the treatment of pyoderma gangrenosum secondary to Crohn's disease. Cutis 1997;60:135-8

24 Wollina U. Clinical management of pyoderma gangrenosum. Am J Clin Dermatol 2002;3:149-58.

25 De Silva BD, Buxton PK. Pneumocystis carinii pneumonia in a patient with pyoderma gangrenosum treated with cyclosporin. $\mathrm{Br} J$ Dermatol 2000; 143:683-4

26 Lyon CC, Kirby B, Griffiths CE. Recalcitrant pyoderma gangrenosum treated with systemic tacrolimus. Br J Dermatol 1999;140:562-4.

27 Teitel AD. Treatment of pyoderma gangrenosum with methotrexate. Cutis 1996; $57: 326-8$

28 Present $\mathrm{DH}$, Rutgeerts $\mathrm{P}$, Targan S, et al. Infliximab for the treatment of fistulas in patients with Crohn's disease. N Engl J Med 1999;340:1398-405.

29 Chaudhari U, Romano P, Mulcahy LD, et al. Efficacy and safety of infliximab monotherapy for plaque-type psoriasis: a randomised trial. Lancet 2001;357:1842-7.

30 Rutgeerts $\mathbf{P}$, van Assche G, Vermeire S. Optimizing anti-TNF treatment in inflammatory bowel disease. Gastroenterology 2004;126:1593-610. 